See discussions, stats, and author profiles for this publication at: https://www.researchgate.net/publication/338838219

\title{
Upgrading the Data2Action Framework: Results Deriving from Its Application in the Printing Industry
}

Chapter · January 2020

DOI: 10.1007/978-3-030-38724-2_20

CITATIONS

0

6 authors, including:

Oliver Stoll

Lucerne University of Applied Sciences and Arts

18 PUBLICATIONS 4 CITATIONS

SEE PROFILE

Mario Rapaccini

University of Florence

75 PUBLICATIONS 598 CITATIONS

SEE PROFILE
READS

49

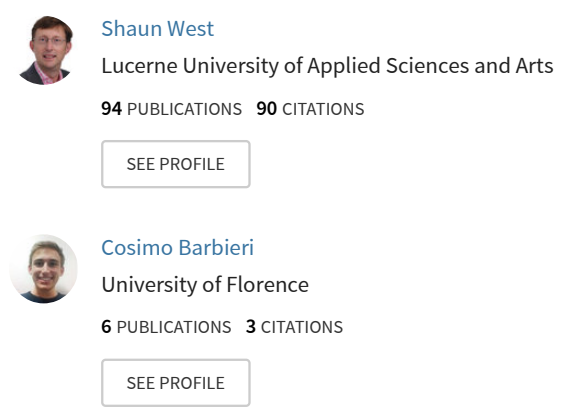

Some of the authors of this publication are also working on these related projects:

Project Pricing of IOT solutions View project

Project Playbook - designing and delivering industrial services View project 


\title{
Upgrading the Data2Action framework: results deriving from its application in the printing industry
}

\author{
Oliver Stoll ${ }^{1}$, Shaun West $^{1}$, Mario Rapaccini ${ }^{2}$, Cosimo Barbieri², \\ Andrea Bonfanti ${ }^{3}$, Andrea Gombac ${ }^{3}$ \\ 1 School of Engineering and Architecture, HSLU Lucerne University of Applied Sciences and \\ Arts, Switzerland \\ oliver.stoll@hslu.ch, shaun.west@hslu.ch \\ 2 School of Engineering, University of Florence \\ mario.rapaccini@unifi.it, cosimo.barbieri@unifi.it \\ 3Ricoh Italia \\ Andrea.Gombac@ricoh.it, Andrea.Bonfanti@ricoh.it

\begin{abstract}
This paper describes the application of the Data2Action (D2A) framework for the development of Smart Print Services. The context for the development was printing-as-a-service in Italy. The firm in this study wanted to create new Smart Services to improve customer experience and drive out waste. The analysis in this paper is based on an Action Research methodology to understand the application of the D2A framework. The results describe the lessons learnt from its implementation, show examples of tools used and reflect on the application of the framework and the individual tools. Using reflections from the development process, an improved framework is proposed that further increases its applicability for use in complex product service systems.
\end{abstract}

Keywords: Smart Services, Servitization, Advanced Services.

\section{Introduction}

Many firms across different industrial segments use digital technologies to enable servitization of complex product service systems (PSS) [1], for example, Canon Ink, 
with its eMaintenance ${ }^{\circledR}$ allows Canon to provide advanced proactive services, e.g., remote diagnostics and consumable management. MAN Trucks [2] uses similar approaches to support owners and operators of lorries to improve operational performance. For this to take place effectively, those developing the digital services have to understand the complex ecosystem of people and equipment that the firm is part of, as well as the operational objectives and the strategy of the customer, whether the customer is the facility owner and/or operator or some other actor.

Collecting field data from an installed base of smarter/connected products is the first move. But more important is how these data can be leveraged to help decision making. Field data from connected products that provide raw information about product condition and usage, are a gold mine, especially if properly integrated with other company data (e.g., sales data, contract entitlements) and external data (e.g., social media, weather forecast). The goal is to transform the information coming from these 'data lakes' into insights that suggest the best actions to be taken, prevent problems, or respond to any need of the people involved in the value creation process. This creates a very complex problem: the right data must be transformed in the right way, so that the right information, in the right form can be delivered to the right person (i.e., the decision-making unit, DMU) [3] at the right time. As the digitization/digital era has flourished, managers have shown growing interest in developing data-driven decision support systems and business intelligence applications, that show analytics and dashboards. These latter are human-machine interfaces (HMIs) [4] that are specifically designed to provide overviews of the key performance indicators (KPIs) and are essential to understanding how business operations are run. Today, the development of data-driven models for descriptive, diagnostic or predictive purposes, which is part of the more articulated practices of Business Performance Management (BPM), can be facilitated by specific methods such as CRISP-DM of IBM [5]. To embrace enlarged views of value co-creation (e.g., business ecosystems, value chain, value constellation) and the paradigms of user-centered design (e.g., design thinking), as well as to focus on smart (digitally-enabled) services as the unit of value creation, the authors have developed the Data2Action (D2A) framework [3]. D2A provides a structure to support understanding of how value is created as key competences, knowledge, data, resources and technologies (e.g., industrial equipment) from different actors in the business ecosystem are integrated. Then D2A helps define how Smart Services can prevent problems/pains and/or produce benefits/gains. Core to this process is the decisional 'cockpit' (i.e., the dashboard) that helps people in shaping the smart service, deciding the actions to be taken and the workflows to be activated.

The paper aims to answer the following research questions (RQs): "How can structured frameworks - such as D2A - support the development of data-driven Smart Services? What are the benefits of adopting these frameworks, against unstructured approaches, in particular in large/complex organizations and processes?" In order to answer the RQ, an action research methodology was applied. 
Upgrading the Data2Action framework: results deriving from its application in the printing industry 3

\section{Background}

The next section briefly reviews the extant theories underpinning the development of data-driven smart services and explains the need for adopting structured approaches such as the D2A framework.

\subsection{Smart services and data-driven decisions}

The term 'Smart Services' can be defined combining the perspective of service dominant logic (SDL) [6] with all the enhancements and innovation that come from digital technologies such as smart connected products, IoT, cloud computing, or predictive analytics [7]. A service is smarter the more it creates value, combining and recombining the available (but scarce) resources in sustainable ways. Technologies are crucial for a smart service business or process to be sustainable [8,9]. As the installed base of manufacturing companies includes more connected products that create huge amounts of field data [10], the focus usually shifts from technologies to how the manufacturer can create value with data. Numerous strategies and possible transformations have been proposed, ranging from selling data [11] to proving smart product-service systems or digital platforms [12], such as in the case of GE Digital. It is agreed that data cannot be used on their own for decision making [7,13,14], but must be elaborated and transformed into information and knowledge $[15,16]$, according to well-shaped processes. The beneficiaries of these processes are people that combine the knowledge they already possess with the newly generated knowledge to develop insights, make conjectures and hypotheses around given facts. Hence, decision making is based on both sense-making (i.e., creating value in the customer's eyes through human judgement) and knowledge-creating processes (i.e., generating insights from huge amounts of field data, as far as they are collected and made available from fleet, people, assets, equipment, etc.). The problem is that value is a subjective, contextdependent construct, that can be largely influenced by the phenomena taking place in non-controllable external environments. This cannot be avoided, as value is generated as value in use, as far as a user interacts and experiences something (e.g., a product, a service process). Therefore, value is created once decisions are acted out $[17,18]$. In other words, data-driven decisions are effective if the corresponding actions (e.g., workflows, processes, tasks) can be viewed as smart services that create value for some beneficiaries. The adoption of structured frameworks can be thus helpful to develop these approaches in complex organizations [19,20], limiting the implications of having data of poor quality [21], or no data at all in a given domain. Structured approaches, in fact, facilitate the linkages between the endpoints of any smart service initiative: what data and for what purpose. In the next subsection, the D2A framework is briefly explained.

\subsection{Data2Action framework}

The Data2Action framework [3] evolved from three projects related to value creation from data in complex systems. It provides a structure to support understanding of the 
ecosystem, the actors and the equipment within it, as well as the interactions between the assets and actors necessary to support the innovation of Smart Services. The framework consists of four steps and continuous refinement: understand; ideate; prototype; and test (see Fig. 1).

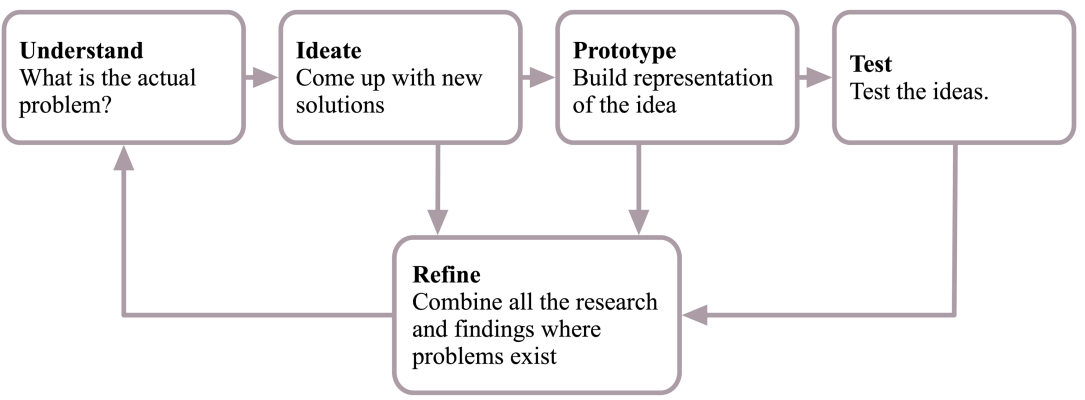

Fig. 1. Overview of the D2A framework

\section{Methodology}

In order to answer the RQ, it is necessary to analyze which improvements the Data2Action framework needs in order to support the decision-making process needed for the development of Smart Services based on the data owned by the company. These processes are becoming increasingly complex, so it is essential to address management research with a qualitative approach [22], which gives the possibility of gaining an understanding of managerial actions and processes in real-life organizational settings [23]. In order to conduct qualitative research, case studies can be applicable especially when the research interest is concerned with the dynamics of a phenomenon [24]. Nonetheless, in order to understand the effect of the Data2Action framework, it has to be applied with the aim of supporting the Smart Services development and improving the performance of the business. For this reason, this paper can be characterized as an action research case study [25].

The action research methodology was applied with the collaboration of Ricoh Italia, the Italian affiliate of Ricoh, a multinational manufacturer of printers. In particular, we collaborated with the service department, which wanted to understand how to develop new Smart Services using the data collected from the individual printers, focusing on how the order fulfillment system could be used to improve customer experience and at the same time drive out waste (i.e., cost or inventory) from their service system.

The collaboration involved a multidisciplinary (service design experts and data scientists) and international (HSLU and University of Florence) team of researchers, and a team of different specializations (IT, service, operation) and different levels of responsibility (director, technician, project manager). Once the whole team was set up, the Data2Action framework was applied starting from the understanding phase and proceeded for a whole year. A continuous conversation was maintained in order to put the contributions of the research into action and relate the theoretical and empirical 
Upgrading the Data2Action framework: results deriving from its application in the printing industry 5

domains. Every week, the two teams had a meeting of 1-2 hours where feedback was provided from both ends in terms of achievements reached and difficulties and problems emerging, for these, deeper discussions were needed to analyze them in detail. Notes and the follow-ups of the meetings were shared in order to validate the research results and develop the framework further.

\section{Results and Initial Findings}

This section first follows the development of the dashboards based on the problem descriptions, then leads on to the reflections and the lessons learnt from the development process. The term dashboard has been used to describe a visual interface that provides information to the consumer of the information.

\subsection{Understanding the problem and development of decision-supporting dashboards}

The development process started with an analysis of the business ecosystem and the service supply chain (Fig. 2). Here, a persistent loss of printer toner cartridges was identified as a problem by following the D2A framework. This was referred to as the "Bermuda Triangle": a place between the reception point of the toner, the stock and the printer at the customer's site.

The "Bermuda Triangle" was investigated closely, revealing different ways for the toner to disappear. For example, the customer stores the toner for later use and simply forgets where it is stored. Alternatively, another person who needs the toner does not know that there is a spare toner stored at the customer site and orders a new one. In this example, the customer does a poor job regarding their management of toners. The customer pays a monthly flat rate (with an agreed minimum number of copies) plus a fee per copy (when the minimum of copies has been reached). Consequently, the customer is not concerned about this problem as long as there are no cost implications for them - they worry only about loss of print services on a printer due to lack of toner.

Another example of wasting toner is that when the toner reaches a certain threshold, for example $20 \%$, the printer either automatically orders a new toner or the customer does. Since the customer has spare toners on-site, the customer can replace the toner immediately. By doing so, the customer wastes $20 \%$ of toner in the cartridge, which is paid for by the supplier.

The supplier has no direct influence on the "Bermuda Triangle" and trying to change the customer behavior is a delicate and difficult task. Therefore, the focus was laid on the supply chain, which could be optimized in a way that reduces the risk of toners getting lost in the "Bermuda Triangle", without cutting the availability of the printing service provided. 


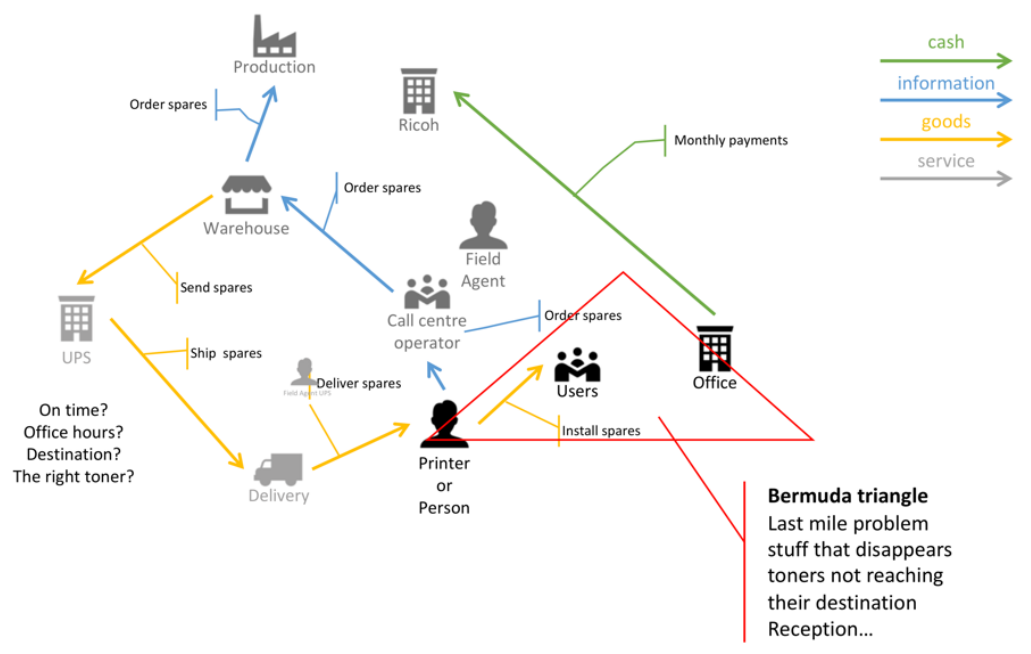

Fig. 2. Analysis of the business ecosystem from a macro perspective

The service delivery was analyzed with the purpose of understanding how the customer or the printer orders toner cartridges. The results should then provide a better understanding of the customer's toner ordering possibilities and Ricoh's toner-request validation process, including the validation support systems (Fig. 3).

The customer has the option of actively ordering the toners by phone, e-mail, eService or by using the automated ordering service. The service either automates the process of ordering or facilitates the ordering process. In the automated service the printer orders the toners autonomously for the customer. In the facilitation version of the service, the machine provides the relevant information the customer needs to provide during the validation process. All toner requests are validated by the "Validation Agent" and by the TVT validation tool from Microsoft.

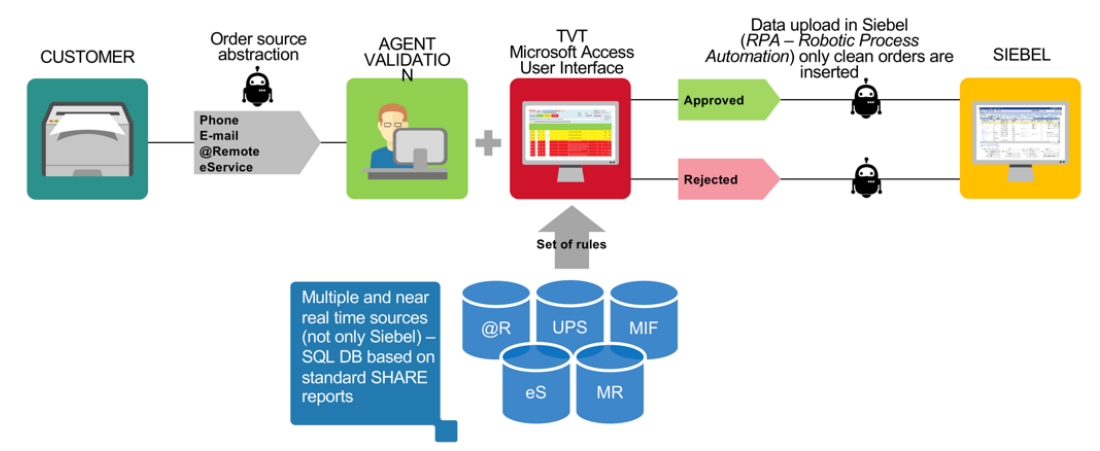

Fig. 3. Toner-request validation process including the validation support systems

The "Validation Agent" for office customers is the Service Operator Call-center (SOC) (Fig. 4), with the SOC being the actor that validates customer requests and the 
Upgrading the Data2Action framework: results deriving from its application in the printing industry 7

user of the validation tool. The SOC as an actor was considered the target for potential digital solutions. The objective of the solutions is to improve the decision-making of the SOC and the decisions must reduce toner waste and/or improve customer experience.

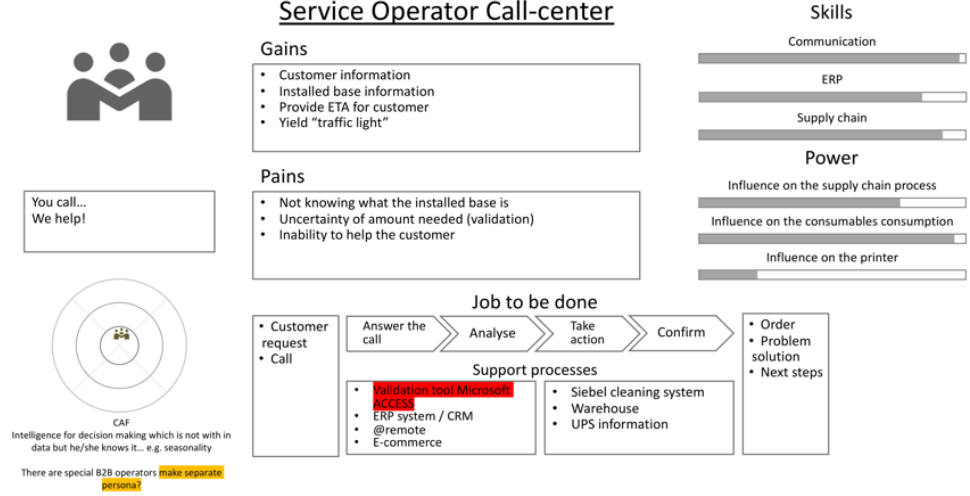

Fig. 4. Most relevant actor for the customer request validation analysis

The final dashboard used Microsoft BI, the solution developed shows the delta of the "Reception Point in Time" (RPiT) and the "Delivery Point in Time" (DPiT) for each serial number of a printer. A negative value represents a delayed delivery and vice versa; the DPiT accuracy was high, however the accuracy of the predicted values was not sufficient for the implementation of an on-time delivery micro-service. However, based on the first coded prototype it was possible to define what data of which quality needs to be collected in the future.

\subsection{Lessons from the analysis of the development process.}

The theoretical frameworks that supported the application of the D2A framework were the three dimensions of SD logic [6], which are relevant for the understanding of the system. The lessons learnt from the understanding phase are shown in Table 1. The key lesson was that a common understanding of the problem could be visually described, allowing experts and managers alike to understand it. The time taken to describe the problem was well spent and formed the basis for the following steps in the D2A framework.

The results of the ideation phase are shown in Table 2. The ideas for solutions included pain relievers and gain creators for the actor, and the description of how the actor solves the problem. The co-ideation provided much better results through the combination of knowledge from the business and technical sides. The level of detail of the ideas grew with the increasing number of iterations. Soon, many ideas were created, but not all could be prototyped.

The ideas were rated on a qualitative basis, using a $2 \times 2$ decision matrix, this assessment tool was developed directly out of the reflection process. The tool uses two 
dimensions for the qualitative value assessment of ideas: feasibility and value. The feasibility valuation was mainly driven by the data-savvy members of the team. The business-people drove the value impact estimation of the ideas within the project.

The Source Target Link Matrix (Fig. 5) is a tool developed and implemented for the D2A framework during the project. The problem was that the desired information from the conceptual dashboards could consist of combinations of different target-data. The connections between the source-data, the target-data and the information desired in the dashboards can be complicated. These connections need to be managed during the development process. The Source Target Link matrix aims to transform the conceptual solutions into a technical perspective. It should help to structure and manage the sourcedata, target-data, analysis methods, and dashboards. The management of source-data includes a list of data that is needed but does not yet exist. Moreover, the matrix allows the combination of different sources and target data, allowing the data to be reused.

The testing phase is shown in Table 4. This phase of the D2A framework was not conducted in sequence to the prototyping phase, rather it was performed in parallel. For reasons of simplicity, the results of this stage are presented separately. Testing the prototypes with the individuals for whom they were developed corroborates their value. People outside the team, who were not the prototype's target audience, struggled to recognize the value of the application. To communicate the value, the context in which the prototype was developed needs to be known to the audience and here an additional tool could be used to support the communication of value.

Table 1. Learnings from the understanding phase

\begin{tabular}{|c|c|c|}
\hline Iteration & What worked... & What did not work... \\
\hline ...iteration 1 & $\begin{array}{l}\text { The theoretical frameworks such as } \\
\text { the three dimensions SD logic and } \\
\text { Service Design Thinking. }\end{array}$ & $\begin{array}{l}\text { Initial usage of the tools by Ricoh (e.g., job- } \\
\text { to-be-done ecosystem mapping, personas } \\
\text { and journey mappings). }\end{array}$ \\
\hline $\begin{array}{l}\text {...adjustments } \\
\text { after iteration } 1\end{array}$ & \multicolumn{2}{|c|}{ Pre-define tools with content to initialize discussion. } \\
\hline ...iteration 2 & $\begin{array}{l}\text { The discussions about the pre-fitted } \\
\text { content provided better results. }\end{array}$ & Cross-disciplinary understanding. \\
\hline $\begin{array}{l}\text {...adjustments } \\
\text { after iteration } 2\end{array}$ & None & \\
\hline$\ldots$ iteration 3 & $\begin{array}{l}\text { Improved cross-disciplinary problem } \\
\text { understanding }\end{array}$ & $\begin{array}{l}\text { People from outside the project group could } \\
\text { not understand the complex ecosystem } \\
\text { visualization. }\end{array}$ \\
\hline $\begin{array}{l}\text {...adjustments } \\
\text { after iteration } 3\end{array}$ & \multicolumn{2}{|c|}{$\begin{array}{l}\text { Dividing the complex ecosystem into smaller ecosystems that could be aggregated } \\
\text { into the complex system. }\end{array}$} \\
\hline ... iteration 4 & $\begin{array}{l}\text { Reduction of complexity of the } \\
\text { ecosystems. }\end{array}$ & $\begin{array}{l}\text { Lack of understanding of data science and } \\
\text { advanced analytics by business-people. }\end{array}$ \\
\hline $\begin{array}{l}\text {...adjustments } \\
\text { after iteration } 4\end{array}$ & \multicolumn{2}{|c|}{ Presentation by Smart Operations on data science and data analysis methods. } \\
\hline
\end{tabular}


Upgrading the Data2Action framework: results deriving from its application in the printing industry 9

Table 2. Lessons from the ideation phase

\begin{tabular}{|c|c|c|}
\hline Iteration & What worked... & What did not work... \\
\hline ...iteration 1 & $\begin{array}{l}\text { Pre-define the tools with content to } \\
\text { initialize discussion. }\end{array}$ & Low quality of ideas. \\
\hline $\begin{array}{l}\text {...adjustments } \\
\text { after iteration } 1\end{array}$ & Co-ideate & \\
\hline ...iteration 2 & $\begin{array}{l}\text { New ideas and problem } \\
\text { understanding through co-ideation. }\end{array}$ & Generic ideas for solutions. \\
\hline $\begin{array}{l}\text {...adjustments } \\
\text { after iteration } 2\end{array}$ & Refine the solutions by visualizing them & $\mathrm{n}$ and adding more details. \\
\hline$\ldots$ iteration 3 & $\begin{array}{l}\text { The refinement of the solutions } \\
\text { revealed more root causes of the } \\
\text { problems. }\end{array}$ & $\begin{array}{l}\text { Too many ideas to choose from for the } \\
\text { prototyping phase; what to do first? }\end{array}$ \\
\hline $\begin{array}{l}\text {...adjustments } \\
\text { after iteration } 3\end{array}$ & Rating the ideas based on a rating matrix & \\
\hline$\ldots$ iteration 4 & $\begin{array}{l}\text { Structured overview of what ideas } \\
\text { to do first }\end{array}$ & Measurable value estimation of the ideas \\
\hline
\end{tabular}

Table 3. Lessons from the prototyping phase

\begin{tabular}{|c|c|c|}
\hline Iteration & What worked... & What did not work... \\
\hline ...iteration 1 & $\begin{array}{l}\text { Prototyping conceptual dashboards } \\
\text { with pen and paper. }\end{array}$ & $\begin{array}{l}\text { Poor feasibility regarding coding the } \\
\text { dashboards was assessed, also because of the } \\
\text { wrong data available or missing data. }\end{array}$ \\
\hline $\begin{array}{l}\text {...adjustments } \\
\text { after iteration } 1\end{array}$ & \multicolumn{2}{|c|}{ Co-development with Smart Operations and HSLU of conceptual prototypes } \\
\hline ...iteration 2 & $\begin{array}{l}\text { Co-development increased the } \\
\text { quality and variety of the } \\
\text { conceptual prototypes. }\end{array}$ & $\begin{array}{l}\text { Handover of the conceptual prototypes to the } \\
\text { data analysts and coders. }\end{array}$ \\
\hline $\begin{array}{l}\text {...adjustments } \\
\text { after iteration } 2\end{array}$ & \multicolumn{2}{|c|}{ Development of the Source Target Link matrix } \\
\hline$\ldots$ iteration 3 & $\begin{array}{l}\text { The handover with the Source } \\
\text { Target Link matrix worked. }\end{array}$ & $\begin{array}{l}\text { Some of the data was not usable for certain } \\
\text { types of analysis which was a surprise for the } \\
\text { OEM. }\end{array}$ \\
\hline $\begin{array}{l}\text {...adjustments } \\
\text { after iteration } 3\end{array}$ & \multicolumn{2}{|c|}{ The D2A needs a section for preliminary data assessment. } \\
\hline ... iteration4 & $\begin{array}{l}\text { Working prototypes for further } \\
\text { refinement. }\end{array}$ & \\
\hline
\end{tabular}


Andrea.Gombac@ricoh.it, Andrea.Bonfanti@ricoh.it

Table 4. Lessons from the testing phase

\begin{tabular}{|c|c|c|}
\hline Iteration & What worked... & What did not work... \\
\hline ...iteration 1 & $\begin{array}{l}\text { Testing by presenting the conceptual } \\
\text { prototypes. }\end{array}$ & $\begin{array}{l}\text { People outside of the project team did } \\
\text { not understand the value delivered by } \\
\text { the prototype. }\end{array}$ \\
\hline $\begin{array}{l}\text {...adjustments } \\
\text { after iteration } 1\end{array}$ & \multicolumn{2}{|c|}{ The presentation of the results needs to offer more context to show its value. } \\
\hline ...iteration 2 & $\begin{array}{l}\text { The actor for whom the solutions were } \\
\text { targeted provided valuable feedback to } \\
\text { improve or redesign both the conceptual } \\
\text { and the working prototypes. }\end{array}$ & $\begin{array}{l}\text { The developers lost focus of the value } \\
\text { and analysis direction due to new } \\
\text { exciting things that were not yet } \\
\text { valuable to the actors. }\end{array}$ \\
\hline $\begin{array}{l}\text {...adjustments } \\
\text { after iteration } 2\end{array}$ & \multicolumn{2}{|c|}{ The testing sprints between prototyping were closer. } \\
\hline
\end{tabular}

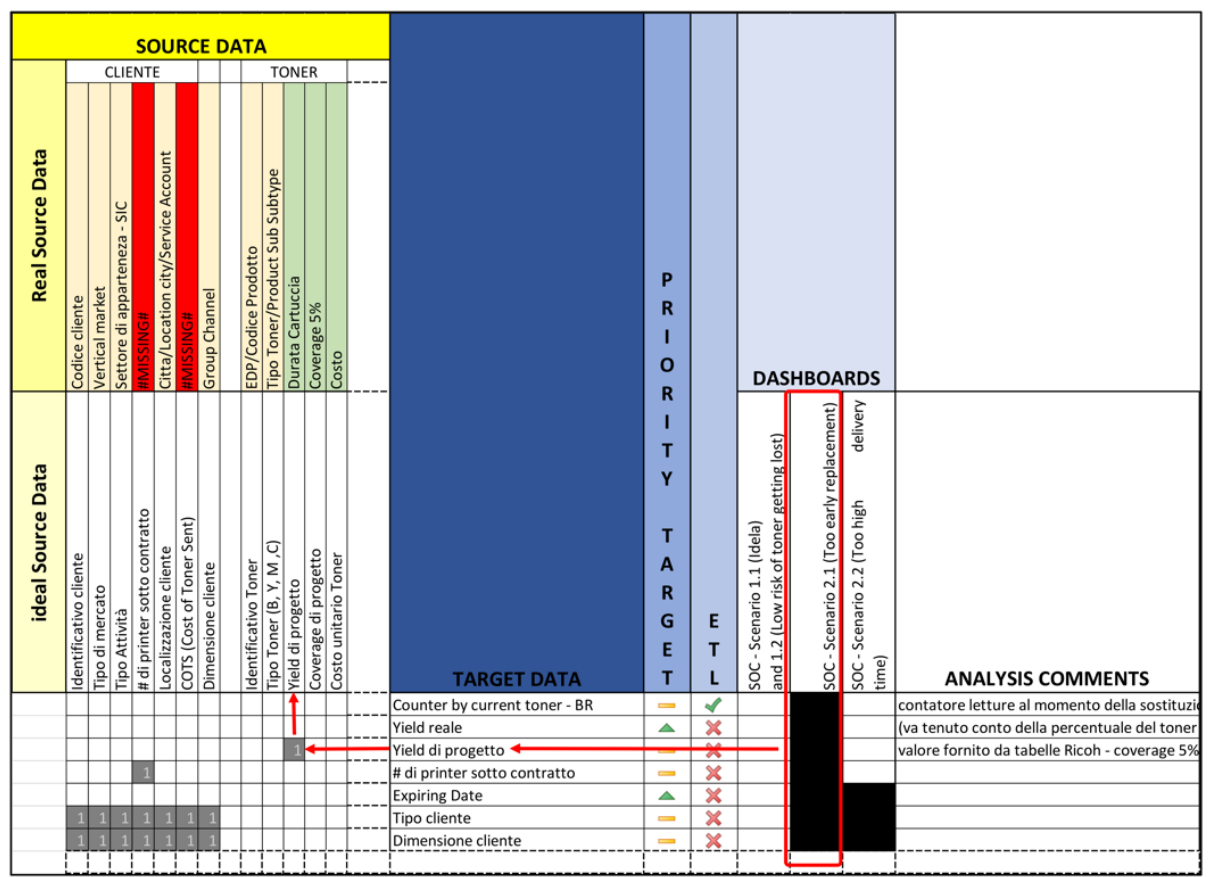

Fig. 5. Source Target Link matrix developed to support coding of dashboards 
Upgrading the Data2Action framework: results deriving from its application in the printing industry 11

\section{Discussion}

This section describes how the D2A framework supported the problem description and how this allowed the solutions to be built and handed over to the data scientists to implement the code in the OEM's service delivery system. The approach is compared to the literature where appropriate and follows the four steps of the D2A framework described in Fig. 1. Fig. 6 shows the updated D2A framework, each of the phases will be discussed below with reflections on the changes made.
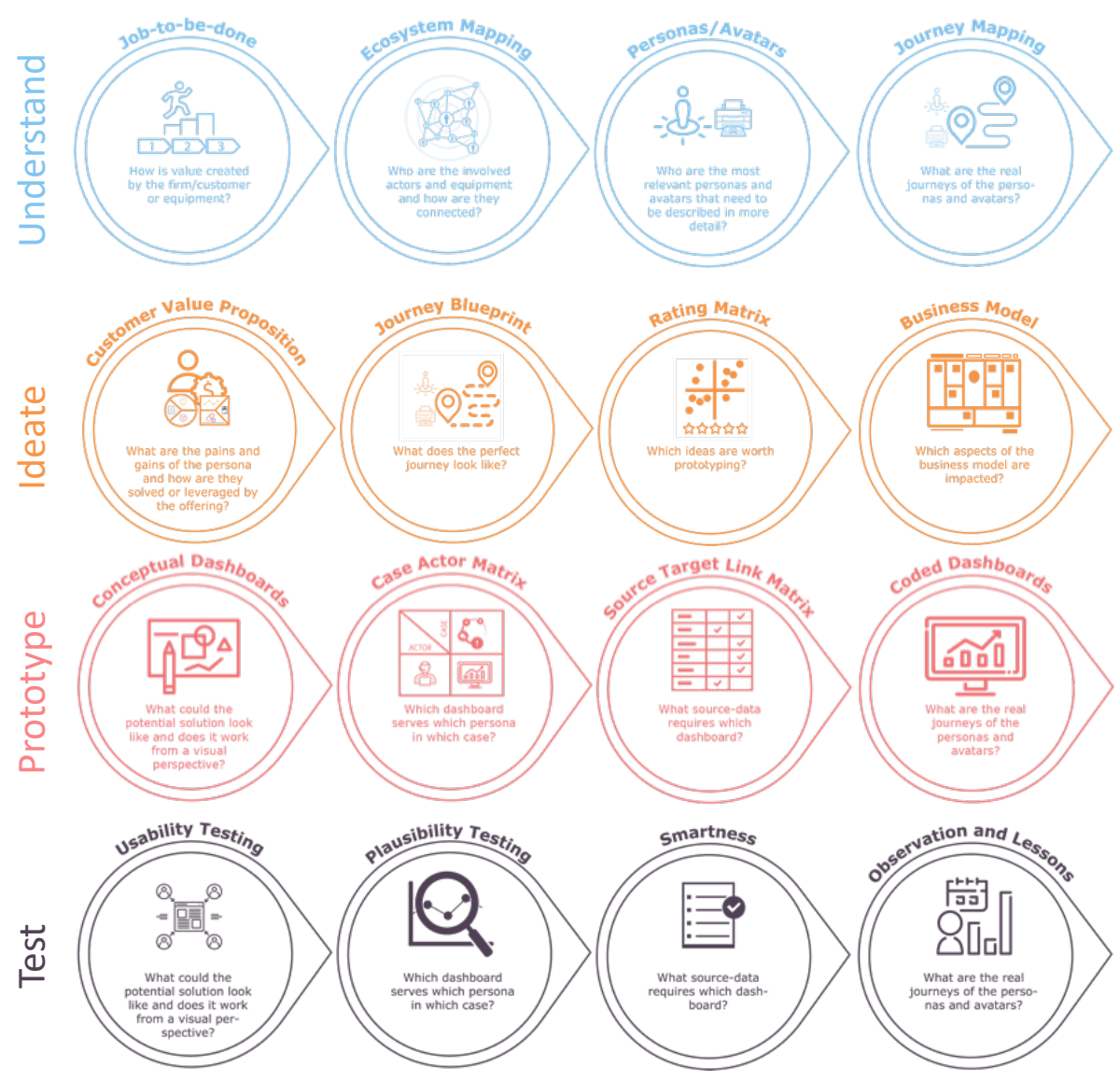

Fig. 6. Tools from the understanding phase of the updated D2A framework

The understanding phase has been updated to improve its capability to define the problem space. The job-to-be-done tool aimed to capture how the customer creates value for the firm's offering. The tool provided the necessary knowledge for both parties about the value creation process within the OEM's customer. The application of the job-to-be-done tool helped to close the knowledge gap between all of those involved. According to the literature [15] the knowledge gap hinders the development 
of digital solutions. Ecosystem mapping helped to identify the relevant actors and equipment and their relations to each other; this then led to the discovery of the "Bermuda Triangle". The visual way of illustrating the problem created a common understanding between all parties. Ecosystem understanding is a fundamental aspect of the development of smart services [8] and PSS [26]. Journey mapping helped identify value creation and when the pains and gains emerge along the journey. The journey mapping also revealed other actors that co-create value [6] with the use of equipment. Personas, avatars and journey maps deepened the understanding of the relevant actors and equipment, including what they do and how they do it, and supported building solutions.

The ideation phase was refined, based on the results of this study, by the addition of a rating matrix and the business model canvas. During the development of individual value propositions, the group learned that there are many value propositions. The customer value proposition tool, in combination with journey mapping, provided the most significant impact in the visualization of value co-creation. The visualizations helped to explain the context in which value was created. The rating matrix tool was added to support idea selection; it has two dimensions: value and feasibility. The two dimensions provided justification and structure for the selection of ideas and allowed open conversions between the data scientists (feasibility axis) and the business leaders (value axis).

The prototyping phase was most effective using hand-drawn conceptual dashboards as this supported co-creating of solutions. The coded dashboards take longer to develop, resulting in longer iteration steps. The Case Actor matrix supports the visualization of the interconnected prototypes with the different actors and situations.

Transferring conceptual dashboards to coded dashboards came with the challenge of data complexity and this challenge was overcome through the Source Target Link matrix. This new tool offered a structured link between the data providers and the information consumers, as well as a tool to identify missing (or incomplete data). The matrix provided a technical perspective on the conceptual dashboards that the coders and data scientists preferred. The literature [27] considers the handover from the conceptual phase to coding to be challenging, and here the D2A framework supports this transition.

The testing phase applied two different layers of testing. First, testing the usability of both the conceptual and the coded dashboards and second, testing the plausibility of the data and the information derived from it. The testing has to run in parallel with the prototype phase as this ensures co-creation. The early testing and the redesigning of dashboards helped to reduce waste [28]. However, given that the results of the testing phase were not well documented by either party, more work should be undertaken here to confirm this hypothesis.

To close the discussion, this paper has identified three changes to the D2A framework that were required for its successful application in print-services. These modifications are based on theory and practical lessons from this use case in printservices. The application of the framework has created value for customers of the service (i.e., customer experiences) and for the supplier (i.e., reduced costs). 
Upgrading the Data2Action framework: results deriving from its application in the printing industry 13

\section{Conclusions and Recommendations}

Business impacts were found from the application of the modified D2A framework. The impacts were found in the improved development process and collaboration of the partners as well as in customer experience and the identification and reduction of waste.

The D2A framework supported the common understanding of the problem and highlighted poor assumptions made in the past; it supported the ideation phase in a positive way, and the idea selection/ranking in a pragmatic way through the addition of two additional tools. It helped with the prototyping phase, particularly with the addition of the Source-Target Link matrix; and, it provided a rudimental testing approach.

It is recommended that the updated D2A framework is applied to new use cases to determine its applicability, and that the testing phase is further improved.

\section{Acknowledgements}

The authors would like to thank Ricoh Italy, SmartOperations, the University of Florence, the Lucerne University of Applied Sciences and Arts and the Swiss Alliance of Data Intensive Services.

\section{References}

[1] Mont, O. K. Clarifying the concept of product-service system. Journal of Cleaner Production. 2002

[2] Evans, D. What servitization did for MAN Truck and Bus UK. 2016.

[3] Stoll, O., West, S.S., Rapaccini, M, \& Mueller-Csernetzky, P. Understanding Wicked Problems to build Smart Solutions. FTAL conference - Industrial Applied Data Science. Lugano. 2018.

[4] Firican, G. Best Practices for Powerful Dashboards. Business Intelligence Journal. 2017

[5] G. Overgoor, M. Chica, W. Rand, and A. Weishampel, "Letting the computers take over: Using Ai to solve marketing problems," Calif. Manage. Rev., 2019.

[6] Vargo, S. L., \& Lusch, R. F. Service-dominant logic: Continuing the evolution. Journal of the Academy of Marketing Science. 2008.

[7] Ardolino, M.; Rapaccini, M.; Saccani, N.; Gaiardelli, P.; Crespi, G.; Ruggeri, C. The role of digital technologies for the service transformation of industrial companies. International Journal of Production Research. 2017.

[8] West, S., Gaiardelli, P., \& Rapaccini, M. Exploring technology-driven service innovation in manufacturing firms through the lens of Service Dominant logic. IFAC-PapersOnLine. 2018.

[9] D. Beverungen, O. Müller, M. Matzner, J. Mendling, and J. vom Brocke, "Conceptualizing smart service systems," Electron. Mark., 2019.

[10] Porter, M. E., \& Heppelmann, J. Managing the Internet of Things : How Smart, Connected Products are Changing the Competitive Landscape. Harvard Business Review. 2014.

[11] D. Opresnik and M. Taisch, "The value of big data in servitization," Int. J. Prod. Econ., 2015.

[12] Z. Liu, X. Ming, W. Song, S. Qiu, and Y. Qu, "A perspective on value co-creation-oriented framework for smart product-service system," in Procedia CIRP. 2018.

[13] Rowley, J. The wisdom hierarchy: Representations of the DIKW hierarchy. Journal of Information Science. 2007.

[14] Liew, A. DIKIW: Data, Information, Knowledge, Intelligence, Wisdom and their Interrelationships. Business Management Dynamics. 2013. 
Andrea.Gombac@ricoh.it, Andrea.Bonfanti@ricoh.it

[15] Choo, C. W. Sensemaking, Knowledge Creation, and Decision Making Organizational Knowing as Emergent Strategy. Strategic Management of Intellectual Capital and Organizational Knowledge. 2001.

[16] Choo, C. W. The Knowing Organization: How Organizations Use Information to Construct Meaning, Create Knowledge, and Make Decisions. 2007.

[17] Keeney, R. L. Value-focused thinking: Identifying decision opportunities and creating alternatives. European Journal of Operational Research. 1996.

[18] Bumblauskas, D., Nold, H., Bumblauskas, P., \& Igou, A. Big data analytics: transforming data to action. Business Process Management Journal. 2017.

[19] Lim, C.-H., Kim, K.H., Kim, M.J., Heo, J.Y., Kim, K.J., Maglio, P.P.: From data to value: A ninefactor framework for data-based value creation in information-intensive services. Int. J. Inf. Manage. 39, 121-135. 2018.

[20] Frost, R. B. Cheng, M. \& Lyons, K. A Multilayer Framework for Service System Analysis. Chapter 13. In P. P. Maglio et al. (eds.), Handbook of Service Science, Volume II, Service Science: Research and Innovations in the Service Economy, https://doi.org/10.1007/978-3-319-98512-1_13. 2019.

[21] Song, Z., Sun, Y., Wan, J., \& Liang, P. Data quality management for service-oriented manufacturing cyber-physical systems. Computers and Electrical Engineering. https://doi.org/10.1016/j.compeleceng.2016.08.010. 2017.

[22] Guercini, S. "New qualitative research methodologies in management", Management Decision, Emerald Group Publishing Ltd., Vol. 52 No. 4, pp. 662-674. 2014

[23] Rynes, S. and Gephart, R.P. "Qualitative research and the Academy of Management Journal”, Academy of Management Journal, August. 2004

[24] Eisenhardt, K.M. and Graebner, M.E. "Theory building from cases: Opportunities and challenges", Academy of Management Journal, Academy of Management, Vol. 50 No. 1, pp. 25-32. 2007

[25] Denscombe, M. The Good Research Guide. Open University Press McGraw-Hill Education. 2010.

[26] Baines, T. S., Lightfoot, H. W., Evans, S., Neely, A., et al. State-of-the-art in product-service systems. Proceedings of the Institution of Mechanical Engineers, Journal of Engineering Manufacture. 2007.

[27] Blosch, M., Osmond, N., \& Norton, D. Enterprise Architects Combine Design Thinking, Lean Startup and Agile to Drive Digital Innovation. Gartner. 2016.

[28] Gustafson, J.W., Jones C.H. \& Pape-Haugaard, L. Designing a Dashboard to Visualize Patient Information. The 16th Scandinavian Conference on Health Informatics, Aalborg, Denmark, 2018 